\title{
Typology of Motivation and Aggression on the Basis of Social Network Variables: Examples of Complementary and Nested Behavioral Types through Conventional Statistics
}

\author{
Alexandra Bekiari, Zoi Anna Nikolaidou, Nikolaos Hasanagas \\ Faculty of Physical Education and Sports Sciences, University of Thessaly, Trikala, Greece \\ Email: sandrab@pe.uth.gr
}

How to cite this paper: Bekiari, A., Nikolaidou, Z.A. and Hasanagas, N. (2017) Typology of Motivation and Aggression on the Basis of Social Network Variables: Examples of Complementary and Nested Behavioral Types through Conventional Statistics. Social Networking, 6, 135-147. https://doi.org/10.4236/sn.2017.62008

Received: March 11, 2017

Accepted: April 23, 2017

Published: April 26, 2017

Copyright $\odot 2017$ by authors and Scientific Research Publishing Inc. This work is licensed under the Creative Commons Attribution International License (CC BY 4.0).

http://creativecommons.org/licenses/by/4.0/

\section{Open Access}

\begin{abstract}
Goal of this research is to suggest a typology of verbal aggressiveness, argumentativeness and motivational climate influence, pointing out examples of complementary types (namely containing no identical components) and nested types (containing identical components). Complete network analysis was conducted in a student class at the Dept. of Physical Education and Sport Sciences, University of Thessaly $(\mathrm{N}=66)$. Standardized questionnaires were used. Network analysis and Principal Component Analysis were implemented using Visone software and SPSS, respectively. Main results were: in the typology of targeting, parameters of motivation climate, verbal aggressiveness and argumentativeness were combined in several types ("affable ambitious", "isolated victim", "isolated ambitious", "lightly victimized" and "severely victimized") which were partially complementary and partially nested into each other. These depict student profiles vary from quite socialized and invulnerable to only isolated and victimized. They also reveal the significance of seeking knowledge acquirement vs. performance. The typology of general involvement (in- and out-degree) contains types tending to be rather nested into each other than complementary which varies from quite integrative to purely deconstructive appearance. This typology depicts the connection of motivation climate (and the subsequently induced familiarity) with verbal aggressiveness without diminishing susceptibility to argumentation. The fact that the typology of targeting is composed of several complementary types while in the typology of general involvement mainly of nested ones, can be attributed to the structural clarity of the former ones (a typology focusing only on targeting is structurally clearer than a typology of general involvement).
\end{abstract}

\section{Keywords}

Verbal Aggressiveness, Argumentativeness, Motivation, Complementary and 
Nested Types

\section{Introduction}

\subsection{Verbal Aggressiveness}

Human-beings communicate with each other in order to exchange information, convey emotions and interact. A dominant definition of verbal aggressiveness is a communication attacking the self-concept of other people and causing psychological pain [1]. The psychological pain includes a plethora of negative feelings such as humiliation, embarrassment, hopelessness, despair, depression and the feeling of inadequacy [2]. Verbal aggression can prove destructive in interpersonal relationships, as it produces emotions like sadness, irritation, anger and discouragement to the recipient, or results in physical aggression and violence [3]. Verbal aggressiveness is correlated with a negative climate in the classroom and little engagement during the lesson [4], restricted satisfaction and intrinsic motivation [5] [6], increasing anxiety [7], negative affective learning [8] [9] [10], decreased interpersonal attraction [11] [12] [13], increasing Machiavellianism [14] and undemocratic style of leadership [14] [15]. Verbal aggressiveness also restricts communication inside or outside the classroom [16] [17]. In the domain of physical education (PE), verbal aggressiveness is negatively correlated to intrinsic motivation and discipline reasons [18] [19] [20] [21] and fair play [22]. Additionally, aggressive communication decreases motivation to study and participation [23] [24] and causes dissatisfaction with learning [25] [26]. Verbal aggressiveness has also been explored in network samples. It proves to be correlated with intimacy and general power relations, physical, social and scientific attraction [27] [28] [29] [30] [31]. Not only determinants and effects but also typologies of aggressiveness attributes were proposed [12] [32] [33].

\subsection{Motivational Climate}

According to Achievement Goals Theory [34], people are motivated to their actions by the need to prove their competence. On this basis, motivational climate is usually defined as the climate created within a classroom encouraging mastery or performance. These are two main orientations concerning one's success or ability. People who are task-orientated, focus on learning and enhancing their skills. The accomplishments are based on subjective criteria. On the contrary, ego-orientated people determine the achieved success by the final result and compare their performance with others' [35]. In the educational context, the mastery motivational climate enhances personal improvement and the cooperation, while the performance oriented climate emphasizes the competitiveness and decreases the tolerance to mistakes in learning procedure [36]. [37] reports that perceptions of mastery motivational climate in the PE class are positively correlated to positive feedback. When the motivational climate in PE class is task- 
oriented, the students feel self-worth, content [38], highly motivated [39] and show effort and persistence to their pursuit [40]. The invigoration of the students' self-confidence promotes the desire to develop their skills; engagement in physical activities and positive attitudes toward exercise [41]. Contrariwise, the use of rivalry by the ego-oriented instructors produces negative emotions, such as pressure and anxiety [42]. In addition, a strong motivation climate leads up to positive experiences and satisfaction in future athletic activities [43]. Mastery motivational climate is positively correlated to the need for developing ability, autonomy and interpersonal relationships [44], cohesiveness [45] and negatively correlated to stress [46].

\subsection{Argumentativeness}

Argumentativeness is defined as a tendency to engage in debatable subjects, to disprove opposing believes and to state personal positions. Individuals with high argumentativeness are more likely to enunciate disagreements and get involved in interpersonal conflicts [2]. Argumentativeness was found to be a constructive trait, as it makes one impose his perspectives on a controversial topic [3]. Argumentative persons perceive arguments as an exciting intellectual challenge and are seen as more credible, creative and self-assured [4]. Argumentativeness is positively related to affective learning, state motivation, interpersonal attraction and satisfaction [4] [6] [24] [47], socio-communicative style and discipline reasons [48], democratic teaching style, intrinsic motivation [9] and negatively with Machiavellianism [14]. Argumentativeness is positively related to the student's state motivation [47] and to physical, social and scientific interpersonal attraction [13]. Network analysis has also been conducted in the field of argumentativeness [29] [32].

\subsection{Structure of the Research}

In this research, the three concepts described above are considered to be interdependent parameters producing different behavioral types. One cannot be completely susceptible to motivation, verbal aggressiveness and argumentativeness all time. Various subtle dimensions of these parameters appear in different combinations constituting respective patterns. These can be either well demarcated from each other or having more or less dimensions in common. In the former case, they are complementary to each other while in the latter one are regarded as (more or less) nested into each other.

The formulation of concrete types is regarded as a rather practical added valued of the paper, enabling to discern certain behavioral patterns appearing in the educational activity. The exploration of complementarity or nestedness of these types is considered to be a meta-analysis of the typology suggested and thus, it can be regarded as a theoretical added value.

Actually, the fulfilment of this practical and theoretical added value is considered to be the main aim and contribution of the paper, the truth of which seems to derive from the statistical facts and its interpretability. 


\section{Method}

Complete network analysis is a method appropriate for exploring interactions, including also aggressiveness and motivation [49] [50]. A class of $\mathbf{n}$ students is visually presented as a polygon. This is a network of $\mathrm{n}$ nodes. The diagonals depict the links among the nodes (e.g. relations of motivation influence, aggressiveness) (e.g. A influences B, A threats B, C and D etc.). However, in order to be algebraically processible and not only illustrative, this network is mathematically expressed as a matrix where the nodes are ordered on both the vertical and horizontal axes. The elements of the matrix are the values of the relations occurring from the vertical to horizontal axis (e.g. from A to B: no existence of motivation influence $=0$, existing motivation influence $=1$ ). The length of a chain of successive relations from $A$ to $D$ (A influences $B, B$ influences $C$ and $C$ influences $D$ ) is also relevant, as it expresses the "Katz status" of node D within the network (formula of Katz, 1953, see also [51]). Thus, the node A possessing the highest Katz status can influence actors $\mathrm{B}, \mathrm{C}$ and $\mathrm{D}$, by initial influencing just $\mathrm{B}$. The Katz status of every other relation can be similarly calculated.

The following algorithms of network analysis were used, calculated and normalized (\%) by network software: in-degree (occasional hierarchy position), outdegree (it expresses the occasional hierarchy position but for outgoing relations, in contrast to the in-degree), degree (the sum of in- and out-degree), Katz status (accumulative hierarchy position), page rank (distributive hierarchy position) and authority (qualified competitiveness). It is also clarified that Katz, page rank and authority are also here calculated on ingoing relations. Their formulas are consolidated and easily accessible in several websites. Their social interpretation is given in previous papers [27] [28] [33].

\subsection{Sample}

Network (so-called "snowball") sampling was conducted. The whole network was a class of 66 students ( ${ }^{\text {rd }}$ semester) from the Department of Physical Education and Sport Sciences of the University of Thessaly in October 2016. It consisted of 34 male and 32 female, aged from 19 to $32(\mathrm{M}=19.3, \mathrm{SD}=0.67)$. The participants originated from a wide range of various regions of Greece. The questionnaires were answered during the lesson and the response rate was $100 \%$. The discrete handling of the questionnaires was emphasized to the students. The answering lasted 20 - 30 minutes. Research ethics was observed. A network sample is of course a non-random one. This is not, however, a weakness, as the goal of the analysis was not descriptive but analytic statistics.

\subsection{Questionnaire}

The network-related part of questionnaire was formulated in the basis of previous similar questionnaires [13] [28] [52]. Nevertheless, it was adjusted to the peculiarities of the particular research. Thus, questions concerning motivation (performance and learning), verbal aggressiveness and, more specifically, argumentation, were added. The non-network-related part of the questionnaire in- 
cluded parameters regarding the individual profile of the participants (e.g. gender, age, socio-economic state). In the particular paper the questionnaires are not presented in annex, as the key words of the questions are already presented in the tables.

\subsection{Statistical Analysis/Processing}

The network variables were calculated by Visone 1.1 software. Both network and non-network variables were processed in cross-sectional analysis by SPSS 21 (Principal Component Analysis). Coefficients higher than 0.300 were considered for extracting typology, as this is considered to yields balanced results (enough parameters to construct types but not so many that it would decrease their explanatory value and make them only descriptive) [28] [53] [54]. This technique is mostly appropriate for extracting general typology (in contrast, for example, to stepwise multivariate analysis which is more appropriate for examining variables in relation to a specific one considered as dependent). The interpretation of the results has been based on in-depth interviews.

\section{Results and Discussion}

In "Figure 1", selected examples of networks are presented. The first column presents the circle form presenting each network as polygon. This enables a visual perception of the density (percentage of all possible relations which exist). The densest network appears to be this of the motivation influence in learning sport (2.4\%). This is understandable as it is in accordance with the formal goal of the Department of Physical Education and Sport Science. The next denser networks are these of motivation influence in improvement (1.5\%) and of argumentativeness $(1.2 \%)$. The thinnest network is that of threat $(0.32 \%)$. This is also expectable as such a verbal aggressiveness necessitates extreme conditions in order to take place and does not massively characterize the everyday life of students.

The next three columns present the pyramids of hierarchy (namely how the nodes are layered according to the position they possess in the indicators of Katz, page rank and authority respectively).

In "Table 1", a typology of targeting in all three relations is presented. This shows how the attributed parameters of motivation climate, verbal aggressiveness and argumentativeness tend to be combined making out behavioral types. The types of the "affable ambitious", the "isolated victim", the "isolated ambitious", the "lightly victimized" and the "severely victimized" are in part complementary (namely quite different from each other completing the whole behavioral patterns appearing in the students class with different parameters) and in part nested into each other (namely, the one can be subtype of the other). Particularly, the "affable ambitious", the "isolated victim" and the "lightly victimized" are purely complementary to each other, as they have no components in common. The "isolated ambitious" is in part nested in the "affable ambitious" as they in common the components of performance (improvement and surpass- 


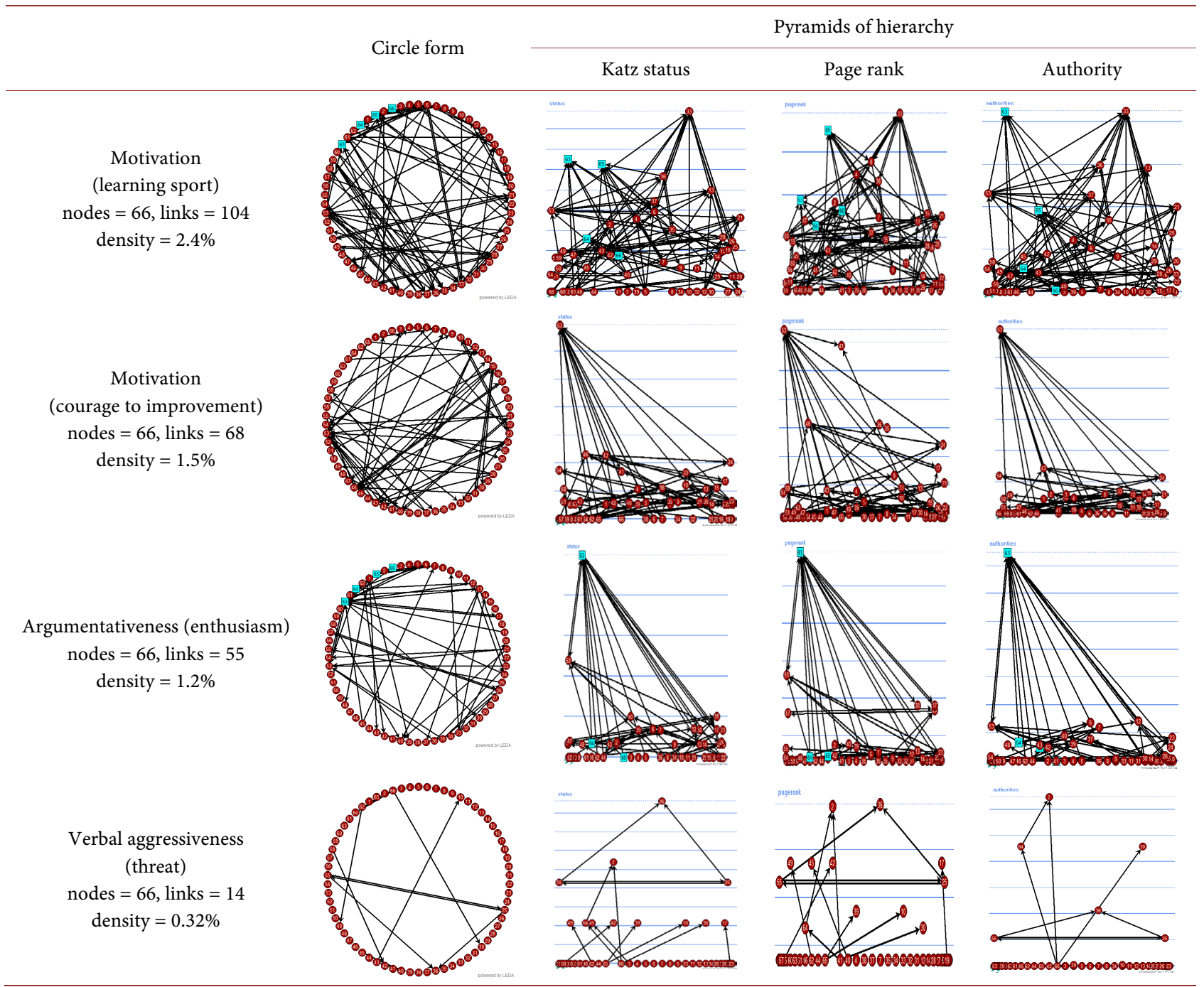

Figure 1. Examples of networks of argumentativeness, motivation influence and verbal aggressiveness in students class of $3^{\text {rd }}$ semester at the Department of Physical Education and Sport Sciences, University of Thessaly, 2016.

ing), and in part in the "isolated victim" having the avoidance of arguing in common. The "lightly victimized" is nested into the "severely victimized" having the deriding in common while the "severely victimized" is purely complementary to the "isolated ambitious" and to the "affable ambitious".

The affable ambitious depicts a student presenting a noticeable interest to learn and to be distinct in terms of learning and improving performance. The combined attitude of both acquiring knowledge (learning) and achieving recognizable results (performance) depicts a tendency to be both perceptive to the scientific subject as cognitive structure itself and compatible to the demands set by the academic and physical education system as criteria for distinction. In other words, the "affable ambitious" students are both cognitively and institutionally affected. Simultaneously, they are susceptible to create enthusiasm and enjoyment during argumentation. It is also noticeable that this type is not significantly targeted by verbal aggressors. Apparently, these students constitute a widely acceptable example. 
The "isolated ambitious" students could be considered to constitute a quasi-subtype of the "affable ambitious" type. However, the "isolated ambitious" students present only a significant tendency to achieve high performance, without showing any significant interest in learning. These students seem to gain the respect of their colleagues, as they are not targeted by verbal aggressors. However, they also do not inspire any positive feeling in argumentation while the others avoid arguing with them. This is understandable, as strict antagonistic students who are just interested in achieving antagonistic performance, without acquiring knowledge are neither perceptive nor attractive for arguments exchange.

The type of the "isolated victim" appears as the opposite end. In contrast to the "affable ambitious" type, the "isolated victim" tends just to become a target of verbal aggression. Almost all forms of verbal aggressiveness are exerted to this type. At the same time, this type does not seem to have any chance of being motivated or of developing argumentation. Thus, it remains quite isolated.

The "lightly victimized" and the "severely victimized" appear to be as complementary types to the "isolated victim". The "lightly victimized" is just a target of deriding. Deriding is a convenient form of verbal aggressiveness among physical education students, as not achieving the desirable performance in physical exercises is a quite discernible phenomenon, and, thus, a quite appropriate occasion for deriding. The "severely victimized" is not only complementary but also in part a subcase of the "isolated victim" as it also attracts rudeness and mockery additionally to deriding. It could also be seen as a normative extension of the behavior the aggressors show to the "lightly victimized". The only difference is a quantitative one. The aggressors believe that in certain cases their aggression should also be enhanced with rudeness and mockery, because only deriding might be too "light". Similar typologies have been proposed in older analyses [28] [53] [54] [55].

In contrast to "Table 1", where only targeting profiles are presented, in "Table 2" a typology of total involvement (sum of indegree and outdegree) is suggested. Three types of students are presented: the "fully integrated", the "extensive brawler" and the "isolated brawler". These types are less and also less distinctive than the types of Table 1 . The second type is a subtype of the first one, and the third one is partially a type of the second one. Thus, it is a nested rather than a distinctive and complementary typology. This is reasonable, as being generally involved lets less distinguishable patterns emerge. Such nested typologies have also emerged under similar conditions in previous analyses [13] [32] [56].

The "fully integrated" students are affected by and affecting others through all parameters of the motivation climate (both learning and performing). Thus, cognitive perceptiveness and conformity to the academic criteria of performance seem to be combined. However, this tendency of full integration also includes "bad moments" of practiced and received verbal aggressiveness. This is understandable, as the extensive contacting and familiarity constructed by the cultiva- 
Table 1. Typology of targeting (sum of indegree, katz, pagerank and authority).

\begin{tabular}{|c|c|c|c|c|c|c|}
\hline & & \multicolumn{5}{|c|}{ Component } \\
\hline & & $\begin{array}{l}\text { The affable } \\
\text { ambitious }\end{array}$ & $\begin{array}{c}\text { The isolated } \\
\text { victim }\end{array}$ & $\begin{array}{l}\text { The isolated } \\
\text { ambitious }\end{array}$ & $\begin{array}{l}\text { The lightly } \\
\text { victimized }\end{array}$ & $\begin{array}{c}\text { The severely } \\
\text { victimized }\end{array}$ \\
\hline \multirow{5}{*}{ Motivation climate } & learningpedag./pshych. issues & 0.953 & -0.150 & -0.161 & 0.019 & -0.080 \\
\hline & learning biological issues & 0.966 & -0.117 & -0.053 & 0.016 & -0.058 \\
\hline & learning sport issues & 0.537 & 0.089 & -0.225 & -0.080 & 0.282 \\
\hline & encouragingimprovement & 0.613 & 0.073 & 0.678 & 0.014 & 0.196 \\
\hline & surpassingothers & 0.701 & -0.041 & 0.548 & -0.185 & 0.031 \\
\hline \multirow{6}{*}{ Verbal aggressiveness } & negativecomments & 0.103 & 0.901 & -0.056 & 0.034 & -0.250 \\
\hline & offense & 0.116 & 0.852 & 0.043 & 0.242 & -0.278 \\
\hline & deriding & 0.034 & 0.027 & 0.181 & 0.811 & 0.460 \\
\hline & rudeness & 0.026 & 0.454 & -0.334 & -0.033 & 0.568 \\
\hline & mockery & 0.079 & 0.321 & -0.182 & -0.508 & 0.446 \\
\hline & threat & 0.024 & 0.849 & -0.217 & 0.057 & -0.040 \\
\hline \multirow{3}{*}{ Argumentativeness } & avoidarguing & 0.258 & 0.533 & 0.541 & -0.195 & 0.014 \\
\hline & enthusiasmtoargue & 0.877 & -0.085 & -0.344 & 0.097 & -0.166 \\
\hline & enjoyingtoargue & 0.854 & -0.141 & -0.339 & 0.088 & -0.031 \\
\hline
\end{tabular}

Extraction Method: Principal Component Analysis; a 5 components extracted.

Table 2. Typology of total involvement (degree).

Component

\begin{tabular}{|c|c|c|c|c|}
\hline & & \multicolumn{3}{|c|}{ Component } \\
\hline & & The fully integrated & The extensive brawler & The isolated brawler \\
\hline \multirow{5}{*}{ Motivation climate } & learningpedag./pshych. issues & 0.762 & -0.488 & 0.080 \\
\hline & learning biologicalissues & 0.802 & -0.461 & 0.072 \\
\hline & learningsportissues & 0.648 & -0.301 & 0.261 \\
\hline & encouragingimprovement & 0.456 & -0.303 & -0.332 \\
\hline & surpassingothers & 0.656 & -0.301 & -0.447 \\
\hline \multirow{6}{*}{ Verbal aggressiveness } & negativecomments & 0.578 & 0.597 & 0.106 \\
\hline & offense & 0.432 & 0.427 & 0.381 \\
\hline & deriding & 0.605 & 0.637 & -0.055 \\
\hline & rudeness & 0.511 & 0.702 & -0.038 \\
\hline & mockery & 0.391 & 0.546 & -0.368 \\
\hline & threat & 0.401 & 0.757 & -0.015 \\
\hline \multirow{3}{*}{ Argumentativeness } & avoidarguing & 0.165 & -0.108 & 0.701 \\
\hline & enthusiasmtoargue & 0.792 & -0.313 & 0.155 \\
\hline & enjoyingtoargue & 0.551 & -0.459 & -0.191 \\
\hline
\end{tabular}

Extraction Method: Principal Component Analysis; a 3 components extracted. 
tion of motivation climate (especially encouraging others) often induces mutual verbal aggressiveness. During physical training there are frequently occasions of antagonism or fail, which are conducive to exerting verbal aggressiveness. Nevertheless, such an involvement in verbal aggressiveness which is combined with stimulation to learn and perform does not seem to impinge a mutual enthusiasm and enjoyment of arguing. Apparently, motivation climate may induce verbal aggressiveness but also saves the communication.

The "extensive brawler" type consists only of the "deconstructive" part of the "fully integrated" type, namely of all parameters of the verbal aggressiveness. The "extensive brawler" is the type of students who are mainly and significantly characterized by being aggressive or a target of aggression. Thus, involvement in verbal aggression may appear not only as a phenomenon induced by motivation climate but also as an autonomous phenomenon. In this case, attractive argumentation can also not be enhanced, however, without clearly avoidance of arguing.

Finally, the "isolated brawler" is a type which is a small part of "extensive brawler" completed also with mutual avoidance of argumentation. This "isolated brawler" is a type structurally quite plain (consisting of only two parameters) but the most "deconstructive" for the communication and the whole socialization. Students who are involved in hard offenses tend also avoid and being avoided for arguing.

\section{Conclusions, Limitations and Points for Further Research}

The practical and theoretical aims of this paper can be considered to be achieved to the extent described below: In the typology of targeting, it was showed that the parameters (components) related with motivation climate, verbal aggressiveness and argumentativeness appeared as combined in certain types ("affable ambitious", "isolated victim", "isolated ambitious", "lightly victimized" and "severely victimized"). These are partially complementary (namely containing no identical components) and partially nested into each other (containing identical components). All these depict a sequence of student profiles varying from quite socialized and invulnerable to clearly isolated and victimized. They also reveal the significance of seeking knowledge acquirement vs. performance. The typology of general involvement (in- and out-degree) is composed of types which tend to be rather nested into each other than complementary. They contain various behavioral profiles, from quite integrative to purely deconstructive. This typology depicts the connection of motivation climate (and the subsequently induced familiarity) with verbal aggressiveness without diminishing susceptibility to argumentation. The fact that in the typology of targeting, there are several complementary types while in the typology of general involvement mainly nested ones, can be attributed to the structural clarity of the former ones (a typology focusing only on targeting is structurally clearer than a typology of general involvement).

As in every project of empirical social research, a limitation and subsequent challenge for further research is to enlarge the sample. This can be achieved by 
applying the questionnaire in more and various departments in the same or different countries. Thus, a cross-disciplinary and cross-national analysis can be tried in future research. The further exploration of complementarity vs. nestedness of the types emerging by enlarging the sample is also a future research question. If the complementarity (clear demarcation of types) increases with the enlargement of the sample, this could be supposed to be evidence that the particular questionnaire has achieved to measure substantially different behavioral dimensions (divergence validity) and not behaviors which are identical or effects of common (individual or social) source.

\section{References}

[1] Infante, D.A. and Wigley, C.J. (1986) Verbal Aggressiveness: An Interpersonal Model and Measure. Communication Monographs, 53, 61-69. https://doi.org/10.1080/03637758609376126

[2] Infante, D.A. (1987) Aggressiveness. In: McCroskey, J.C. and Daly, J.A., Eds., Personality and Interpersonal Communication, Sage, Newbury Park, CA, 157-192.

[3] Infante, D.A. and Rancer, A.S. (1996) Argumentativeness and Verbal Aggressiveness: A Review of Recent Theory and Research. Annals of the International Communication Association, 19, 319-352. https://doi.org/10.1080/23808985.1996.11678934

[4] Rancer, A.S. and Avtgis, T.A. (2006) Argumentative and Aggressive Communication: Theory, Research, and Application. Sage Publications, Thousand Oaks.

[5] Bekiari, A. and Syrmpas, I. (2015) Coaches' Verbal Aggressiveness and Motivational Climate as Predictors of Athletes' Satisfaction. British Journal of Education, Society \& Behavioural Science, 9, 318-329. https://doi.org/10.9734/BJESBS/2015/17757

[6] Manoli, P. and Bekiari, A. (2015) EFL Teachers' Verbal Aggressiveness and Students' Intrinsic Motivation and Social-Affective Strategy Use: Investigating Possible Relations. Advances in Research, 5, 1-13. https://doi.org/10.9734/AIR/2015/19692

[7] Bekiari, A., Patsiaouras, A., Kokaridas, D. and Sakellariou, K. (2006) The Relationship between Verbal Aggressiveness and State Anxiety in Volleyball. Psychological Reports, 99, 630-634.

[8] Bekiari, A. (2012) Perceptions of Instructors' Verbal Aggressiveness and Physical Education Students' Affective Learning. Perceptual and Motor Skills, 115, 325-335. https://doi.org/10.2466/06.11.16.PMS.115.4.325-335

[9] Bekiari, A. and Manoli, P. (2016) EFL Teacher Verbal Aggressiveness and Argumentativeness and Student Socio-Affective Strategy Use and Affective Learning: Exploring Possible Associations. Journal of Teacher Education and Educators, 5, 154-171.

[10] Bekiari, A. and Tsaggopoulou, Th. (2016) Verbal Aggressiveness and Affective Learning in Physical Education. Advances in Physical Education, 6, 406-418. https://doi.org/10.4236/ape.2016.64041

[11] Bekiari, A. and Petanidis, D. (2016) Exploring Teachers' Verbal Aggressiveness through Interpersonal Attraction and Students' Intrinsic Motivation. Open Journal of Social Sciences, 4, 72-85. https://doi.org/10.4236/jss.2016.412007

[12] Bekiari, A. and Spyropoulou, S. (2016) Exploration of Verbal Aggressiveness and Interpersonal Attraction through Social Network Analysis: Using University Physical Education Class as an Illustration. Open Journal of Social Sciences, 4, 145-155. https://doi.org/10.4236/jss.2016.46016 
[13] Syrmpas, I. and Bekiari, A. (2015) The Relationship between Perceived Physical Education Teacher's Verbal Aggressiveness and Argumentativeness with Students' Interpersonal Attraction. Inquiries in Sport \& Physical Education, 13, 21-32.

[14] Bekiari, A. (2016) Insights into Instructors' Verbal Aggressiveness and Students' Machiavellianism through Leadership Style and Motivational Climate. European Scientific Journal, 12, 90-110. https://doi.org/10.19044/esj.2016.v12n25p90

[15] Bekiari, A. (2014) Verbal Aggressiveness and Leadership Style of Sports Instructors and their Relationship with Athletes' Intrisic Motivation. Creative Education, 5, 114-121. https://doi.org/10.4236/ce.2014.52018

[16] Bekiari, A., Digelidis, N. and Sakellariou, K. (2006) Perceived Verbal Aggressiveness of Coaches in Volleyball and Basketball: A Preliminary Study. Psychological Reports, 103, 526-530.

[17] Myers, S.A., Edwards, C., Wahl, T.S. and Martin, M.M. (2007) The Relationship between Perceived Instructor Aggressive Communication and College Student Involvement. Communication Education, 56, 495-508.

https://doi.org/10.1080/03634520701466398

[18] Bekiari, A., Perkos, S. and Gerodimos, V. (2015) Verbal Aggression in Basketball: Perceived Coach Use and Athlete Intrinsic and Extrinsic Motivation. Journal of Physical Education and Sport, 15, 96-102.

[19] Bekiari, A., Kokaridas, D. and Sakellariou, K. (2005) Verbal Aggressiveness of Physical Education Teachers and Students' Self-Reports of Behaviour. Psychological Reports, 96, 493-498. https://doi.org/10.2466/pr0.96.2.493-498

[20] Bekiari, A., Kokaridas, D. and Sakellariou, K. (2006) Associations of Students' SelfReports of Their Teacher's Verbal Aggression, Intrinsic Motivation, and Perceptions of Reasons for Discipline in Greek Physical Education Classes. Psychological Reports, 98, 451-461. https://doi.org/10.2466/pr0.98.2.451-461

[21] Bekiari, A. and Tsiana, I. (2016) Exploring Instructors' Verbal Aggressiveness and Students' Personal Orientations and Reasons of Discipline in Physical Education Class. Advances in Physical Education, 6, 158-168. https://doi.org/10.4236/ape.2016.63018

[22] Hassandra, M., Bekiari, A. and Sakellariou, K. (2007) Physical Education Teacher's Verbal Aggression and Student's Fair Play Behaviors. The Physical Educator, 64, 94-101.

[23] Rocca, A. (2004) College Student Attendance: Impact of Instructor Immediacy and Verbal Aggression. Communication Education, 53, 185-195. https://doi.org/10.1080/03634520410001682447

[24] Myers, S.A. and Rocca, K.A. (2000) Students' State Motivation and Instructors' Use of Verbally Aggressive Messages. Psychological Reports, 87, 291-294. https://doi.org/10.2466/pr0.2000.87.1.291

[25] Bekiari, A. and Sakellariou, K. (2003) Perceived Instructor Verbal Aggressiveness and Student State Learning in Physical Education. Italian Journal of Sport Sciences, 1, 251-256.

[26] Myers, S.A. (2002) Perceived Aggressive Instructor Communication and Student State Motivation, Learning, and Satisfaction. Communication Reports, 15, 113-121. https://doi.org/10.1080/08934210209367758

[27] Bekiari, A. and Hasanagas, N. (2016) Suggesting Indicators of Superficiality and Purity in Verbal Aggressiveness: An Application in Adult Education Class Networks of Prisoners. Open Journal of Social Sciences, 4, 279-292. https://doi.org/10.4236/jss.2016.43035 
[28] Bekiari, A. and Hasanagas, N. (2015) Verbal Aggressiveness Exploration through Complete Social Network Analysis: Using Physical Education Students' Class as an Illustration. International Journal of Social Science Studies, 3, 30-49. https://doi.org/10.11114/ijsss.v3i3.729

[29] Bekiari, A., Deliligka, S. and Koustelios, A. (2017) Examining Relations of Aggressive Communication in Social Networks. Social Networking, 6, 38-52. https://doi.org/10.4236/sn.2017.61003

[30] Hasanagas, N. and Bekiari, A. (2015) Depicting Determinants and Effects of Intimacy and Verbal Aggressiveness Target through Social Network Analysis. Sociology Mind, 5, 162-175. https://doi.org/10.4236/sm.2015.53015

[31] Hasanagas, N. and Bekiari, A. (2017) An Exploration of the Relation between Hunting and Aggressiveness: Using Inmates Networks at Prison Secondary School as an Illustration. Social Networking, 6, 19-37. https://doi.org/10.4236/sn.2017.61002

[32] Bekiari, A., Deliligka, S. and Hasanagas, N. (2017) Analyzing Networks of Verbal Aggressiveness and Motivation. Psychology, 8, 495-515.

https://doi.org/10.4236/psych.2017.83031

[33] Theoharis, D., Bekiari, A. and Koustelios, A. (2017) Exploration of Determinants of Verbal Aggressiveness and Leadership through Network Analysis and Conventional Statistics. Using School Class as an Illustration. Sociology Mind, 7, 27-43. https://doi.org/10.4236/sm.2017.72003

[34] Nicholls, J.G. (1984) Achievement Motivation: Conceptions of Ability, Subjective Experience, Task Choice, and Performance. Psychological Review, 91, 328-346. https://doi.org/10.1037/0033-295X.91.3.328

[35] Sit, C.H.P. and Lindner, K.J. (2005) Motivational Orientations in Youth Sport Participation: Using Achievement Goal Theory and Reversal Theory. Personality and Individual Differences, 38, 605-618.

[36] Newton, M., Duda, J.L. and Yin, Z. (2000) Examination of the Psychometric Properties of the Perceived Motivational Climate in Sport Questionnaire-2 in a Sample of Female Athletes. Journal of Sports Sciences, 18, 275-290. https://doi.org/10.1080/026404100365018

[37] Stein, J., Bloom, G.A. and Sabiston, C.M. (2012) Influence of Perceived and Preferred Coach Feedback on Youth Athletes' Perceptions of Team Motivational Climate. Psychology of Sport and Exercise, 13, 484-490.

[38] Vazou, S., Ntoumanis, N. and Duda, J.L. (2006) Predicting Young Athletes' Motivational Indices as a Function of Their Perceptions of the Coach- and Peer-Created Climate. Psychology of Sport and Exercise, 7, 215-233.

[39] Joesaar, H., Hein, V. and Hagger, M.S. (2011) Youth Athletes' Perception of Autonomy Support from the Coach, Peer Motivational Climate and Intrinsic Motivation in Sport Setting: One Year Effects. Psychology of Sport and Exercise, 13, $257-$ 262.

[40] Bortoli, L., Bertollo, M., Comani, S. and Robazza, C. (2011) Competence, Achievement Goals, Motivational Climate, and Pleasant Psychobiosocial States in Youth Sport. Journal of Sports Sciences, 29, 171-180.

https://doi.org/10.1080/02640414.2010.530675

[41] Jaakkola, T., Washington, T. and Yli-Piipari, S. (2012) The Association between Motivation in School Physical Education and Self-Reported Physical Activity during Finnish Junior High School: A Self-Determination Theory Approach. European Physical Education Review, 19, 1-15.

[42] Escarti, A. and Gutierrez, M. (2001) Influence of the Motivational Climate in Phys- 
ical Education on the Intention to Practice Physical Activity or Sport. European Journal of Sport Science, 1, 1-12. https://doi.org/10.1080/17461390100071406

[43] Atkins, M.R., Johnson, M.D., Force, E.C. and Petrie, T.A. (2015) Peers, Parents and Coaches, Oh My! The Relation of the Motivational Climate to Boys' Intention to Continue in Sport. Psychology of Sport and Exercise, 16, 170-180.

[44] Alvarez, M.S., Balaguer, I., Castillo, I. and Duda, J.L. (2012) The Coach-Created Motivational Climate, Young Athletes' Well-Being, and Intentions to Continue Participation. Journal of Clinical Sport Psychology, 6, 166-179. https://doi.org/10.1123/jcsp.6.2.166

[45] Horn, T.S., Byrd, M., Martin, E. and Young, C. (2012) Perceived Motivational Climate and Team Cohesion in Adolescent Athletes. Sport Science Review, 21, 25-49. https://doi.org/10.2478/v10237-012-0009-3

[46] Smith, R.E., Smoll, F.L. and Cumming, S.P. (2007) Effects of a Motivational Climate Intervention for Coaches on Young Athletes' Sport Performance Anxiety. Journal of Sport \& Exercise Psychology, 29, 39-59. https://doi.org/10.1123/jsep.29.1.39

[47] Myers, S.A. and Rocca, K.A. (2001) Perceived Instructor Argumentativeness and Verbal Aggressiveness in the College Classroom: Effects on Student Perceptions of Climate, Apprehension, State Motivation. Western Journal of Communication, 65, 113-137. https://doi.org/10.1080/10570310109374696

[48] Bekiari, A. and Pylarinou, M. (2017) Instructor Argumentativeness and SocioCommunicative Style and Student Discipline: Using Physical Education Students' Class as an Illustration. Open Journal of Social Sciences, 5, 122-136. https://doi.org/10.4236/jss.2017.53011

[49] Bekiari, A. and Hasanagas, N. (2016) Sociological Insights in the Education System: "Unlocking" the Power Relations. Thessaloniki, AfoiKyriakidi Editions S.A.

[50] Bekiari, A. and Hasanagas, N. (2016) "Educating” in Physical Education. Theoretical Approaches and Practical Inquiries. Thessaloniki, AfoiKyriakidi Editions S.A.

[51] Bickson, D. and Malkhi, D. (2008) A Unifying Framework of Rating Users and Data Items in Peer-to-Peer and Social Networks. Peer-to-Peer Networking and Applications, 1, 93. https://doi.org/10.1007/s12083-008-0008-4

[52] Bekiari, A. and Digelidis, N. (2015) Measuring Verbal Aggressiveness in Sport and Education. International Journal of Physical Education, 52, 12-21.

[53] Theoharis, D. and Bekiari, A. (2016) The Influence of Mathematics and Learning Environment in Verbal Aggressiveness and Interpersonal Relations: A Dynamic Analysis of Social Networks. Proceedings of the 8 th International Congress Mathematical Society, Thessaloniki, 30 March 3 April 2016, 415-428.

[54] Theoharis, D. and Bekiari, A. (2016) Social Networks Analysis of Centrality: Case Study in Leadership Networks. Proceedings of the 33rd Congress Greek Mathematical Society (with International Participation), Chania, 4-6 November 2016, 250 260.

[55] Bekiari, A., Hasanagas, N., Theoharis, D., Kefalas, I. and Vasilou, A. (2015) The Role of Mathematical Object and the Educational Environment to Students' Interpersonal Relationships: An Application of Full Social Network Analysis. Proceedings of the 32 nd Congress Greek Mathematical Society (with International Participation), Kastoria, 799-812.

[56] Theoharis, D. and Bekiari, A. (2017) Cumulative Hierarchy Analysis (Katz Centrality) on Leadership Networks of Learning Communities. Proceedings of the 9 th International Congress Mathematical Society, Thessaloniki, 17-19 March 2017, 285297. 
Submit or recommend next manuscript to SCIRP and we will provide best service for you:

Accepting pre-submission inquiries through Email, Facebook, LinkedIn, Twitter, etc. A wide selection of journals (inclusive of 9 subjects, more than 200 journals)

Providing 24-hour high-quality service

User-friendly online submission system

Fair and swift peer-review system

Efficient typesetting and proofreading procedure

Display of the result of downloads and visits, as well as the number of cited articles Maximum dissemination of your research work

Submit your manuscript at: http://papersubmission.scirp.org/

Or contact $\underline{\text { sn@scirp.org }}$ 